\title{
Çocuk yoğun bakım ünitesinde akut hipoksi nedeniyle yatan hastaların yakın dönem nörolojik takibi
}

\section{Recent neurological outcomes of patients admitted to pediatric intensive care unit for acute hypoxia}

\author{
Mutlu Uysal YAZICI*1], Fatih Mehmet Akif ÖZDEMIR²@, Ülkühan ÖZTOPRAK²@, Ebru AZAPAĞASI"ם,

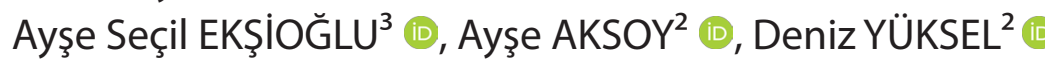

'Sağlık Bilimleri Üniversitesi, Dr. Sami Ulus Kadın Doğum Çocuk Sağlığı ve Hastalıkları Eğitim ve Araştırma Hastanesi, Pediatri Yoğun Bakım Kliniği, Ankara/TÜRKiYE

${ }^{2}$ Sağıık Bilimleri Üniversitesi, Dr. Sami Ulus Kadın Doğum Çocuk Sağlığı ve Hastalıkları Eğitim ve Araştırma Hastanesi, Çocuk Nöroloji Kliniği, Ankara/TÜRKiYE

${ }^{3}$ Sağıık Bilimleri Üniversitesi, Dr. Sami Ulus Kadın Doğum Çocuk Sağlı̆ı ve Hastalıkları Eğitim ve Araştırma Hastanesi, Radyoloji Kliniği, Ankara/TÜRKiYE

\section{Öz}

Amaç: Beyin kan akımını ve dokulara oksijen sunumunu etkileyen çeşitli durumlarda (boğulma, arrest, asfiksi gibi) gelişebilen hipoksik iskemik beyin hasarı önemli bir morbidite ve mortalite nedenidir. Bu çalışmanın amacı son iki yılda çocuk yoğun bakım ünitesi'nde akut hipoksi nedeniyle yatan hastaların etyoloji, klinik özellikler, tedavi ve yakın dönem nörolojik takip sonuçlarının değerlendirilmesidir.

Gereç ve Yöntemler: Çalışmaya Mayıs2017- Nisan 2019 tarihleri arasında ÇYBÜ'ye yatııılan 1 ay-18 yaş arası daha öncesinden sağlıklı, mental ve motor gelişim basamakları normal olan akut hipoksi nedeniyle yatıılan 25 hasta alındı. ÇYBÜ'de arrest sonrası değerlendirme için Pediatrik Serebral Performans Kategori Skorlama Sistemi (PCPC) kullanıldı.

Bulgular: Hastaların geliş Glaskow koma skalası (GKS) median:6 (min:3 max:15) iken; yoğun bakımdan çıkış GKS: 10 (min:6 max:15) olarak tespit edildi $(p<0,05)$.. Hastaların arrest olduktan hemen sonra kan gazında asidozda oldukları, Hco3'ün belirgin düşük olduğu,pH: (min:6.91 - max: 7.49); Laktat'ın yüksek (min:8 - max: 145); AST'nin min:21 - max:712 ve CK'nın yüksek (min:47 - max:3351) olduğunu ve ÇYBÜ'ye yatırılıp hızlıca uygun tedavi başlandıktan 24 saat sonra hastaların asidozdan çıktı̆̆ı pH: (min:7.23 - max:7.61); AST (min:15 - max:83) ;ALT (min:6 - max:45)ve CK (min:16 - max:258) ve Laktat'ın (min:8 - max:93) gerilediğini gördük ve bu sonuçlar istatiksel olarak anlamlı saptandı.( $p<0,05)$

Sonuç: Akut Hipoksinin patofizyolojisinin iyi anlaşılması, erken dönemde tedavi stratejilerinin geliştirilerek beynin hasardan korunması gereklidir.Olguların nörolojik izlemi ve yardımcı görüntüleme tetkikleri ile hasarın ciddiyeti ve prognoz üzerine etkileri araştırılıp en uygun tedavi yapılmalıdır. Akut hipoksiden geçen çocuklarda nörolojik sekel riskini en aza indirmek için hastalar resusitasyon sonrası en erken dönmede ÇYBÜ'ye yatırıımalı ve multidisipliner tedavi edilmelidir.

Anahtar kelimeler: akut hipoksi; nörolojik sonuç; çocuk; yoğun bakım

Sorumlu Yazar*: Mutlu Uysal YAZıCl, Sağlık Bilimleri Üniversitesi, Dr. Sami Ulus Kadın Doğum Çocuk Sağlığı ve Hastalıkları Eğitim ve Araştırma Hastanesi, Pediatri Yoğun Bakım Kliniği, Ankara/TÜRKiYE

E-posta: mutluuysal@yahoo.com

ORCID: 0000-0001-7377-4718

Recevied: 18.06.2019 accepted: 19.08 .2019

Doi: $10.18663 / \mathrm{tjcl} .578865$ 


\begin{abstract}
Aim: Hypoxic ischemic brain injury is an important cause of morbidity and mortality in all age groups. It may develop in various conditions (such as drowning, arrest, asphyxia ) affecting brain blood flow and oxygen supply to tissues. The aim of this study was to evaluate the etiology, clinical features, treatment and recent neurological follow-up outcomes of the patients hospitalized for acute hypoxia in the pediatric intensive care unit (PICU) in the last two years.
\end{abstract}

Material and Methods: The study included 25 patients whose age was 1 month-18 years and hospitalized in the PICU with complaint of acute hypoxia in between May 2017 and April 2019. The patients were previously having normal mental and motor development levels. Pediatric Cerebral Performance Category Scoring System (PCPC) was used for evaluation.

Results: The median Glaskow coma scale (GCS) was 6 (min: 3 max: 15) at admission compared with the median GCS: 10 (min: 6 max: 15) at the time of discharge from PICU $(p<0,05)$. The tests immediately after the cardiac arrest revealed that the patients were in acidosis in blood gas test pH: (min:6.91 - max: 7.49);, Hco3 was lower, Laktat was high (min:8 - max: 145); AST (min:21 - max:712) ve CK was high (min:47 - max:3351) compared with the results measured 24 hours after the appropriate treatment was started the patients were released from acidosis pH: (min:7.23 - max:7.61); AST (min:15 max:83) ;ALT (min:6 - max:45)ve CK (min:16 - max:258) ve Laktat'ın (min:8 - max:93) were measured as in between normal limits and the differences were found to be statistically significant $(p<0.05)$.

Conclusion: It is necessary to understand the pathophysiology of acute hypoxia and to protect the brain from damage by developing treatment strategies in the early period. The most appropriate treatment should be started while making close neurological follow up and trying to understand the severity of damage and effects on prognosis of these patients. To minimize the risk of neurological sequelae in pediatric patients undergoing acute hypoxia, in earlier period of admission these patients should be hospitalized in the PICU and managed by multidisciplinary team.

Keywords: acute hypoxia, neurological outcome, pediatric intensive care unit

\section{Giriş}

Hipoksi dokuya taşınan oksijen miktarında azalma olup, iskemi dokuya glikoz ve oksijen ulaştırımasını engelleyen kan akımındaki parsiyel veya tam yokluktur. Beyin kan akımını ve dokulara oksijen sunumunu etkileyen çeşitli durumlarda( boğulma, arrest, asfiksi gibi) gelişebilen hipoksik iskemik beyin hasarı her yaş grubunda önemli bir morbidite ve mortalite nedenidir. Çocuk Yoğun Bakım ünitesi'nde sıklıkla karşısşılan hipoksik iskemik beyin hasarı sonrasında prognostik durumun değerlendirilmesi uzamış hastane yatışı, maliyet ve bakım veren aile için kaygı uyandırmaktadır [1, 2]. Çocuk Yoğun Bakım Ünitesi'ne resüsitasyon yapılarak yatırılan bu hastaların uzun dönemde bilişsel ve motor alanda sekel gelişme riski yüksektir.Ingiltere'de yapılmış bir çalışmada çocuklarda travmatik olmayan komanın yani akut hipoksinin insidansı 30/100.000 olarak bildirilmiştir [3]. Hipoksi ve iskemiye en hassas organ olan beyinde aynı anda birçok yolakta gelişen biyokimyasal olaylar zinciri hücre hasarına giden süreci başlatır. Patofizyolojisinin iyi anlaşılması, erken dönemde tedavi stratejilerinin geliştirilerek beynin hasardan korunması gereklidir. Olguların yakın nörolojik izlemi ve yardımcı görüntüleme tetkikleri ile hasarın ciddiyeti ve prognoz üzerine etkileri anlaşılmaya çalışılarak en uygun tedavi yaklaşımı belirlenmeye çalışıı $[4,5]$. Bu çalışmanın amacı son iki yılda çocuk yoğun bakım ünitesi'nde akut hipoksi nedeniyle yatan hastaların etyoloji, klinik özellikler, tedavi ve yakın dönem nörolojik takip sonuçlarının değerlendirilmesidir.

\section{Gereç ve Yöntemler}

Çalışmaya Mayıs 2017- Nisan 2019 tarihleri arasında çocuk yoğun bakım ünitesi'ne yatıılan 1 ay-18 yaş arası daha öncesinden sağlıklı, mental ve motor gelişim basamakları normal olan akut hipoksi nedeniyle yatırılan 25 hasta alındı. Her hasta için demografik veriler, etyoloji, klinik, laboratuvar ve görüntüleme bulguları, tedavi ve yakın dönem nörolojik takiplerini içeren formlar dolduruldu.Hipoksi etyolojisinde; yabancı cisim aspirasyonu, ası, suda boğulma, arrest, şok, akut hava yolu obstrüksiyonu olan olgular dahil edildi. Travmatik, hemorajik, enfeksiyöz, metabolik ve kardiyak nedenle arrest olan olgular çalışmaya dahil edilmedi. Daha önceden nörolojik hastalığı ya da altta yatan kronik bir hastalığı olan olgular çalışmaya dahil edilmedi. ÇYBÜ'de arrest sonrası değerlendirme için Pediatrik Serebral Performans Kategori Skorlama Sistemi (PCPC) kullanıldı.Bu skorlama sistemi 1-6 puan arasında değişmektedir. 1: normal 2: ılımlı engellilik 3: orta derecede engellilik 4: ağır derecede engellilik 5: koma veya vejetatif state 6: beyin ölümü. şeklindedir. Tüm hastalar 
çocuk yoğun bakımdan çıkarken bu sınıflama kullanılarak değerlendirildi. Sayısal verilerin normal dağılım durumu Kolmogorov-Smirnow ve Shapiro-Wilk testleriyle, normal dağılım göstermeyen sayısal verilerin dağılımı ortanca (min- max) şeklinde gösterildi. Normal dağılım göstermeyen bağımlı sayısal değişkenler arasındaki farklar Wilcoxon testi ile değerlendirildi. Çalışma için hastanemiz etik kurulundan onay alınmıştır ve çalışmamız Helsinki Illkeler Deklerasyonuna uyularak gerçekleştirilmiştir. Tüm hasta ebeveynlerinden bilgilendirilmiş onarm formları alınmıştır.

\section{Bulgular}

Çalışmaya daha öncesinden sağlıkı olan 11 kız, 14 erkek olmak üzere toplam 25 hasta dahil edildi. Ortanca yaşları 13 ay ( min: 1 ay max: 16 yaş) idi.Hipoksi etyolojisi ise sırayla şu şekildeydi ; Hastane dışı arrest (15 hasta) , 5 hasta akut gelişen hava yolu obstüksiyonu, 2 hasta suda boğulma, 2 hasta başka hastanelerde iyi tedavi edilememiş hipovolemik şok ve 1 hastada da yabanci cisim aspirasyonu mevcuttu. Akut hipoksiden geçen hastaların 6'sında aspirasyon ve aspirasyon pnömonisi tespit edildi.

Hastaların geliş Glaskow koma skalası (GKS) median:6 ( min: 3 max: 15 ) iken; yoğun bakımdan çıkıs GKS: 10 ( min: 6 max: 15 ) olarak tespit edildi.Kardiyopulmoner resüsitasyon 18 hastaya uygulanmış olup, ortanca resüsitasyon süresi 15 dak idi. (min: 10 dak maximal 60 dak) Çocuk yoğun Bakım ünitesinde 18 hastaya invaziv mekanik ventilasyon uygulanmış olup, 7 hastanın rezervuarlı maske ile oksijen tedavisi aldığı gözlendi.

Hastaların çocuk yoğun bakıma yatıştaki ilk muayenesinde; pupil incelemesi sonucu direk ışık refleksi 18 hastada bilateral pozitif alınıken, 7 hastada alınamadı. 13 hastada pupiller izokorik iken, , 6 hastada pupiller myotik, 6 hastada fix dilateydi. Hastaların geliş kan gazlarında ortanca pH: 7.1 ( min: 6,9 max: 7,3) , laktat düzeyi $46 \mathrm{mMol} / \mathrm{L}(\min : 8$ max: 145 )ve HCO3 düzeyleri 13 ( min: 4 max : 25 ) olarak bulundu. Hipoksi sonrasında hastaların Çybü'ye yatıştaki ve 24 saat sonraki laboratuar değerleri Tablo 1 'de gösterilmiştir (Tablo 1).
Tablo 1'e detaylı bakıldığında hastaların arrest olduktan hemen sonra kan gazında asidozda oldukları, Hco3'ün belirgin düşük olduğu,Laktat'ın yüksek, AST'nin ve CK'nın yüksek olduğunu ve Çocuk Yoğun Bakım Ünitesi'ne yatırılıp hızlıca uygun tedavi başlandıktan 24 saat sonra hastaların asidozdan çıktığı, kan pH'sının, AST/ALT/CK değerlerinin ve Laktatın hızlıca normale geldiğini görmekteyiz ve bu sonuçlar istatiksel olarak anlamlı saptandı. $(p<0,05)$

25 hastanın çocuk yoğun bakımda ortanca yatış süresi : 10 gün (min:4 gün - max:85 gün )saptanırken, toplam hastanede yatış süresi ortancası 20 gün (min: 8max:140 gün )olarak görüldü.

25 hastanın 6 tanesi ilk 72 saat içinde ex olurken, 19 hastanın yoğun bakım tedavisi tamamlanıp servislere devredildi. Ex olan hastaların geliş GKS: 3 ve resüsitasyon süresi 30 dakikadan uzundu, ilk nörolojik muayenelerinde ışık refleksi alınmıyordu ve pupiller fix dilate olarak görüldü,destek tedavisine rağmen nörolojik muayene bulgularında değişiklik olmadı,3 hastaya beyin ölümü tanısı koyuldu fakat aile organ donasyonu olmayı kabul etmedi. Diğer 3 hasta nazokomiyal enfeksiyonlar nedeniyle kaybedildi.Çocuk yoğun izleminde nörolojik muayene ve radyolojik olarak beyin ödemi saptanan 16 hastaya antiödem tedavi olarak hipertonik salin (\%3 NaCl) ve başa 30 derece elevasyon uygulandı .

Akut Hipoksiden geçen hastalar hemodinamik olarak stabillendikten ve hipoksi üzerinden 5-7 gün geçtikten sonra nöroradyolojik görüntüleme ve eş zamanlı olarak EEG çekilerek beyin aktivitesi değerlendirildi.Hastaların nöroradyolojik görüntülenmesinde 10 hastada sadece bazal ganglion tutulumu ( Şekil 1a ve 1b), 6 hastada ise hemisferik tutulum (Şekil 2a ve 2b) 9 hastada bazal ganglion ve watershed sulama alanlarında tutulum (Şekil 3 a ve $3 b$ ) saptandı. Elektroensefalografik incelemesinde ise; toplamda 18 hastaya yoğun bakımda şartlarında hasta başında EEG çekilebildi, bunlardan bir tanesi yoğun artefakt nedeniyle net değerlendirilemedi, geriye kalan 7 hastanın bulguları normal sınırlardaydı. Yedi hastada zemin aktivitesinde anormallik

\begin{tabular}{|c|c|c|c|c|c|}
\hline & ÇYBÜ ilk Yatış ortanca & (min - maks) & ÇYBÜ 24 Saat sonraki ortanca & (min-maks) & $\mathbf{p}$ \\
\hline $\mathrm{HCO}_{3(n}$ & 18 & $4-30$ & 24 & $17-47$ & 0.002 \\
\hline Laktat (mMol/L) & 26 & $8-145$ & 17 & $8-93$ & 0.001 \\
\hline pH & 7.27 & $6.91-7.49$ & 7.40 & $7.23-7.61$ & $<0.001$ \\
\hline AST (IU/L) & 118 & $21-712$ & 83 & $15-551$ & 0.004 \\
\hline ALT (IU/L) & 68 & $7-299$ & 45 & $6-223$ & 0.09 \\
\hline CK & 669 & $47-3351$ & 258 & $16-18745$ & 0.37 \\
\hline CK-MB & 92 & $10-745$ & 58 & $13-641$ & 0.17 \\
\hline Troponin & 0.07 & $0-1.17$ & 0 & $0-6.73$ & 0.40 \\
\hline
\end{tabular}


saptanırken bunlardan 3'üne aynı zamanda epileptik anormallik de eşik ediyordu. Toplamda 6 hastada epileptik anormalliğin varlığı saptandı.

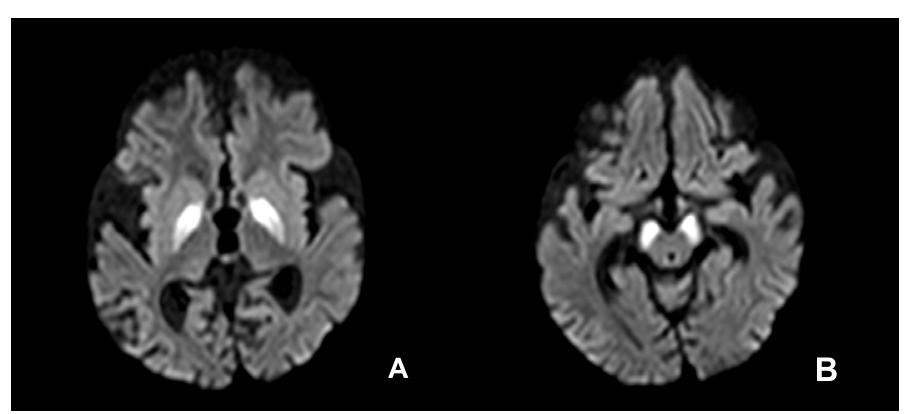

Şekil 1: Bilateral Globus Pallidusda (a) ve serebral pedinküllerde (b) diffüzyon kısıtlaması gösteren akut hipoksik değişikliklerle uyumlu alanlar izlenmektedir.

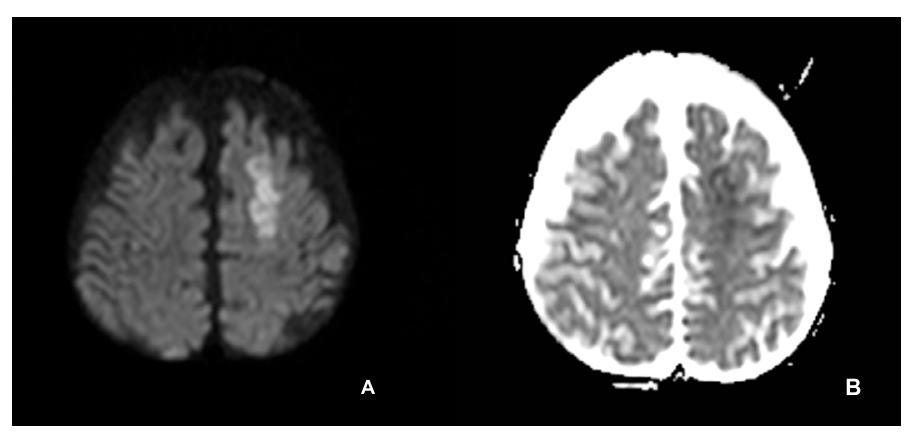

Şekil 2: a: 800 b: (ADC) sekanslarda diffüzyon ağırlıklı incelemede sol sentrumsemiovale düzeyinde, sol paryetal bölgede subkortikalderin beyaz cevher alanlarında akut iskemi ile uyumlu diffüzyon kıstlanması gözlenmektedir.

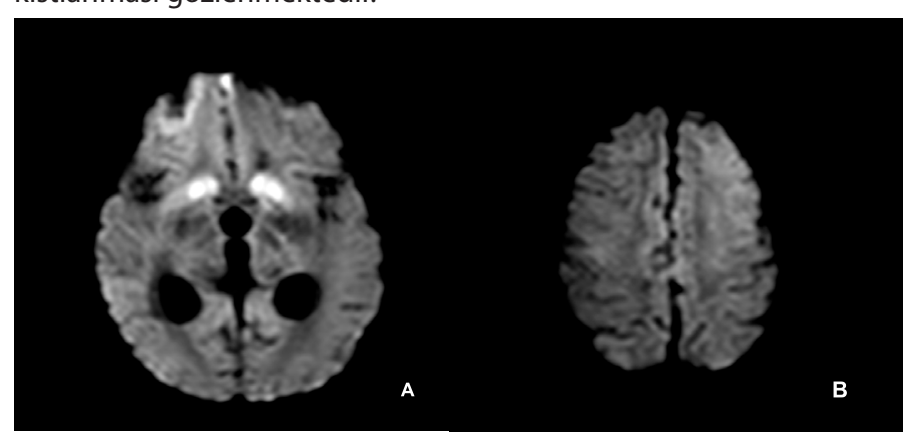

Şekil 3: a: Bazal gangliyon düzeyinde b: sol yüksek paryetal bölgede kortikal düzeyde akut iskemiye sekonder kısıtlanmış diffüzyon alanları gösterilmiştir.

18 tane hasta mekanik ventilasyonda izlenirken, 6 hastaya trakeostomi açıldı,12 hasta ekstübe edildi. 4 hastaya gastrostomi takıldı.6 hastaya trakeostomi ve ev tipi ventilatör desteği verildi. 12 hastaya akut konvülziyon nedeniyle antiepileptik tedavi uygulandı.Hiçbir hastaya terapötik hipotermi tedavisi uygulanmadı. Çocuk nöroloji takiplerinde yatış ve taburculuk sonrası en az 1 yıllık sürelik izlemde bu hastalardan antiepileptik tedavi başlanan 12 hastanın sadece 3 tanesinde semptomatik epilepsi tanısı koyulup uzun süreli antiepileptik ilaç aldığı görüldü. 3 hastada tetraparezi, 4 hastaya da paraparezi nedeniyle antispazmodik tedavi verildi. Bütün hastalara yattıkları süre boyunca fizik tedavi uygulandı, ayaklarına istirahat splinti takıldı ve tüm ailelere fizik tedavi,aspirasyon ve beslenme eğitimi verildi.

ÇYBÜ'de arrest sonrası değerlendirme için Pediatrik Serebral Performans Kategori Skorlama Sistemi (PCPC) kullanıldı. Bu skorlama sistemine göre hastalarımızın PCPC özellikleri tablo 2 de gösterilmiştir (Tablo 2).

\begin{tabular}{|c|c|c|c|c|c|c|}
\hline & $\begin{array}{c}1 \\
\text { Normal }\end{array}$ & $\begin{array}{c}2 \\
\text { Hafif } \\
\text { Disability }\end{array}$ & $\begin{array}{c}3 \\
\text { Orta } \\
\text { Disability }\end{array}$ & $\begin{array}{c}4 \\
\text { Ağır } \\
\text { Disability }\end{array}$ & $\begin{array}{c}5 \\
\text { Koma }\end{array}$ & $\begin{array}{c}6 \\
\text { Beyin } \\
\text { Ölümü }\end{array}$ \\
\hline $\begin{array}{l}\text { Hasta } \\
\text { Sayısı }\end{array}$ & 9 & 2 & 4 & 6 & 1 & 3 \\
\hline
\end{tabular}

\section{Sonuçta;}

25 hastanın 6 tanesi ÇYBÜ'de yatarken ilk 72 saat içinde ex oldu, geriye kalan 19 hastanın 6'sı trakeostomi ve ev tipi ventilatör ile evine gönderildi, 3 hasta tetraparezi olarak izlendi, \%36 kötü nörolojik prognoz görülürken, 10 hastada (\%45 ) iyi nörolojik prognoz izlendi.

\section{Tartışma}

Bu çalışmada iki yıllık süreçte akut hipoksi ile kabul edilen öncesinde sağlıklı olan 25 olgunun verileri incelenmiş olup; 25 hastanın 6 tanesi ilk 72 saat içinde ex olurken, 19 hastanın yoğun bakım tedavisi tamamlanıp servislere devredildi. 18 tane hasta mekanik ventilasyonda izlenirken, 6 hastaya trakeostomi açıldı,12 hasta ekstübe edildi. 4 hastaya gastrostomi takıldı.6 hastaya trakeostomi ve ev tipi ventilatör desteği verildi. 12 hastaya akut konvülziyon nedeniyle antiepileptik tedavi uygulandı.

Çocuk yoğun Bakım Ünitesi(ÇYBÜ)'ne akut hipoksi nedeniyle yatan hastalarda beyin hasarına yol açan(travma, arrest, boğulma, ası, hava yolu obstrüksiyonu gibi)nedenler gösterilmiştir. Tedavide önemli olan primer beyin hasarından çok sekonder beyin hasarı gelişmesini önlemektir. [6]. Primer beyin hasarı olay yerinde olmuştur, ÇYBÜ'de izlenirken hastaların nöbet kontrolü sağlanmalı, hiponatremi, hipokalsemi, hipoglisemi ve asidoz gibi durumların düzeltilmesi, hipotansiyon gelişmesi önlenmeli, ateşi düşürülmeli, gerekliyse antiödem tedavi başlanmalı,hastalarda serebral perfüzyon basınıcını korumak için ortalama arteryel 
tansiyon yükseltilmeli ve kafa içi basınç düşürülmeye çalışılmalıdır. Kafa içi basınç düşürmek için baş 30C eleve edilir, hipertonik salin tedavisi başlanır ve hasta entübe ise end-tidal CO2 seviyesi ölçülerek beyin perfüzyonu optimal sağlanmaya çalışılır. [7]. Tüm hastalara optimal solunum ve kardiyak destek verildi, ılımlı hipokapni ile beraber hiperventilasyon uygulandı. arteriyel CO2 düzeyi 30-35 arasında tutuldu.

Akut hipoksi ile ÇYBÜ'ye kabul edilen hastalarda nörolojik sekel ve prognozu belirleyen önemli faktörler: geliş GKS, uygulanan resüsistasyon süresi, hastane dışı arrest olması ve ilk 72 saat içinde verilen uygun yoğun bakım bakım tedavisidir.Fransa'da çok merkezli yapılan bir çalışmada üçyılda akut hipoksi öyküsü olan 57 hasta alınmış, başvurudan ilk 24 saat içinde 12 hasta ex olmuş, 3 hasta uyanmış ve 42 hastanın nörolojik durumları takip edilmiş, \%38 oranında iyi nörolojik prognoz gösterilmiş. Yine aynı çalışmada resüsitasyon süresi $>10$ dakikadan uzun olması, geliş GKS $<5$ en kötü prognoza sahip olan hastalar olarak bildirilmiş. ( pozitif prediktif değer:\%91,\%100, sensitivite $\% 50, \% 54$ bulunmuş [2]. Bizim çalışmamızda ilk 72 saatte 6 hasta(\%24) ex oldu, 6 hasta uyandı, 9 hasta tam sekelsiz yoğun bakımdan taburcu edildi.Literatürde Hipoksik iskemik ensefalopati de mortalite \%34-\%73 oranında bildirilmiştir [8]. Bizim çalışmamızda mortalite \%24 olarak görüldü.

Arrest sonrası ÇYBÜ'de izlenilen hastaların morbidite ve mortalitesi çok yüksektir ve uzamış yatış süresi nazokomiyal enfeksiyonlar ve ciddi bir maliyete yol açmaktadır. Ronko ve arkadaşlarının yaptığı bir çalışmada akut hipoksi sonrası yaşayan serebral palsili çocukların hastanede yatış maliyeti serebral palsili çocuk başına 100.000 dolar iken , kaybedilen çocuklar için bu maliyet 10.667 dolar olarak bildirilmiştir. [9]. Akut hipoksi sonrası rehabilitasyon ihtiyacı olan çocukların hastanede yatış süreleri uzundur ve maliyeti yüksektir.

Akut hipoksik hasar sonrası prognozu uzun dönemde belirleyen faktörler ise evde oksijen desteği , nazogastrik tüple ya da gastrostomi ile beslenme, trakeostomi ve ev tipi ventilatör olup olmamasıdır. 2017 yılında yenidoğan yoğun bakımda yapılmış 79 hastanın dahil edildiği bir prospektif çalışmada akut hipoksiden 72 saat sonra organ yetmezliğinin eşlik ettiği en sık da solunum ve kardiyak yetmezlik görüldüğü bildirilmiş. asidoz süresi ve derinliği ne kadar ağırsa o kadar çok organ yetmezliği görüldüğü söylenmiş [10].Bizim çalışmamızda 6 hastada >4 organ yetmezliği, 3 hastada 3 organ yetmezliği saptanırken 2 hastada da 2 organ yetmezliği görüldü. En sık görülen organ yetmezlikleri solunum ve hepatik yemezlik iken bunu kardiyak yetmezlik takip ediyordu.
Çalışmanın kısıtlılıkları retrospektif kohort çalışması olması ve vaka sayısnın az olmasıdır. Akut hipoksi ile başvuran hastaların çocuk yoğun bakımdan taburculuk sonrası uzun dönemde nörolojik takip ve radyolojik görüntüleme yapılmaması da diğer bir kısıtlılık olarak değerlendirilebilir.

\section{Sonuç}

Çalışmamızda ; iki yıllık süreçte akut hipoksi ile kabul edilen öncesinde sağlıklı olan 25 olgunun verileri incelenmiş olup \%36 kötü nörolojik prognoz görülürken, 10 hastada ( \%45 ) iyi nörolojik prognoz izlendi.

\section{Maddi destek ve çıkar ilişkisi:}

Çalışmayı maddi olarak destekleyen kişi/kuruluş yoktur ve yazarların herhangi bir çıkara dayalı ilişkisi yoktur.

\section{Kaynaklar:}

1. Kitai $Y$ et al. Long-term outcome of childhood hypoxic-ischemic encephalopathy. No To Hattatsu 2015; 47: 43-48.

2. Mandel, R et al. Prediction of outcome after hypoxic-ischemic encephalopathy: a prospective clinical and electrophysiologic study. J Pediatr 2002; 141: 45-50.

3. Wong CP et al. Incidence, aetiology, and outcome of nontraumatic coma: a population based study. Arch Dis Child 2001; 84: 193-99.

4. Abend NS, Licht DJ. Predicting outcome in children with hypoxic ischemic encephalopathy. Pediatr Crit Care Med 2008; 9: 32-39.

5. Polat İK et al. Hipoksik İskemik Beyin Hasarı. Turkiye Klinikleri J Pediatr Sci 2018; 14: 30-36.

6. Kochanek PM et al. Cerebral resuscitation after traumatic brain injury and cardiopulmonary arrest in infants and children in the new millennium. Pediatr Clin North Am 2001; 48: 661-81.

7. Moler FW et al. Multicenter cohort study of out-of-hospital pediatric cardiac arrest. Crit Care Med 2011; 39: 141-49.

8. Carter BG, Taylor A, Butt W. Severe brain injury in children: longterm outcome and its prediction using somatosensory evoked potentials (SEPs). Intensive Care Med 1999; 25: 722-28.

9. Ronco R et al. Outcome and cost at a children's hospital following resuscitation for out-of-hospital cardiopulmonary arrest. Arch Pediatr Adolesc Med 1995; 149: 210-14.

10. Alsina M et al. The Severity of Hypoxic-Ischemic Encephalopathy Correlates With Multiple Organ Dysfunction in the Hypothermia Era. Pediatr Crit Care Med 2017; 18: 234-40. 